\title{
Understanding of the Elemental Diffusion Behavior in Concentrated Solid Solution Alloys
}

\author{
Chuan Zhang ${ }^{1} \cdot$ Fan Zhang $^{1} \cdot \mathrm{Ke} \mathrm{Jin}^{2} \cdot \mathrm{Hongbin} \mathrm{Bei}^{2} \cdot$ Shuanglin Chen $^{1} \cdot$ \\ Weisheng Cao ${ }^{1} \cdot J^{\prime} \mathrm{Zhu}^{1} \cdot$ Duchao Lv ${ }^{1}$
}

Submitted: 13 April 2017/in revised form: 20 June 2017/Published online: 13 July 2017

(C) ASM International 2017

\begin{abstract}
As one of the core effects on the high-temperature structural stability, the so-called "sluggish diffusion effect" in high-entropy alloy (HEA) has attracted much attention. Experimental investigations on the diffusion kinetics have been carried out in a few HEA systems, such as $\mathrm{Al}-\mathrm{Co}-\mathrm{Cr}-\mathrm{Fe}-\mathrm{Ni}$ and $\mathrm{Co}-\mathrm{Cr}-\mathrm{Fe}-\mathrm{Mn}-\mathrm{Ni}$. However, the mechanisms behind this effect remain unclear. To better understand the diffusion kinetics of the HEAs, a combined computational/experimental approach is employed in the current study. In the present work, a self-consistent atomic mobility database is developed for the face-centered cubic (fcc) phase of the Co-Cr-Fe-Mn-Ni quinary system. The simulated diffusion coefficients and concentration profiles using this database can well describe the experimental data both from this work and the literatures. The validated mobility database is then used to calculate the tracer diffusion coefficients of $\mathrm{Ni}$ in the subsystems of the Co-Cr-Fe$\mathrm{Mn}-\mathrm{Ni}$ system with equiatomic ratios. The comparisons of these calculated diffusion coefficients reveal that the diffusion of $\mathrm{Ni}$ is not inevitably more sluggish with increasing number of components in the subsystem even with homologous temperature. Taking advantage of computational thermodynamics, the diffusivities of alloying elements with composition and/or temperature are also calculated. These calculations provide us an overall picture of the diffusion kinetics within the $\mathrm{Co}-\mathrm{Cr}-\mathrm{Fe}-\mathrm{Mn}-\mathrm{Ni}$ system.
\end{abstract}

Chuan Zhang

Chuan.Zhang@computherm.com

1 CompuTherm LLC, 8401 Greenway Blvd., Suite 248, Middleton, WI 53562, USA

2 Materials Science and Technology Division, Oak Ridge National Laboratory, Oak Ridge, TN 37831, USA
Keywords atomic mobility database - CALPHAD . computational thermodynamics $\cdot$ high entropy alloy sluggish diffusivity $\cdot$ solid solution alloy

\section{Introduction}

The design of conventional alloys is usually based on one or, at most two principal elements with the addition of minor alloying elements to modify their microstructures and properties. While the concept of high-entropy alloy $(\text { HEA) })^{[1]}$ (or multi-principal element alloy (MPEA) ${ }^{[2]}$ ) has revolutionized the format of traditional alloy design by using multi-principal components $(\geq 5)$ with equal or nearequal atomic ratios. This alloy design concept opens a vast unexplored compositional region from where alloys with unique properties may be developed. Key findings on HEAs in the past decade have been summarized by Miracle and Senkov. ${ }^{[3]}$ Many promising properties of HEAs have been reported, such as high hardness, outstanding wear resistance, excellent high-temperature strength, and good thermal stability. These properties are directly related to the four so-called "core effects": high entropy, sluggish diffusion, severe lattice distortion, and cocktail effects. Among these effects, the sluggish diffusion effect is very important and is believed to be responsible for their unique features like excellent thermal stability, decelerated grain growth and formation of nano-precipitates. ${ }^{[4]}$ Thus, understanding the diffusion kinetics of HEAs is very important and of high relevance for their composition optimization and processing control.

Despite the importance of the sluggish diffusion effect of HEAs, only limited experimental data have been reported in the literature due to the difficulties of measurement. Tsai et al. $^{[4]}$ experimentally studied the 
interdiffusion coefficients in the Co-Cr-Fe-Mn-Ni alloys

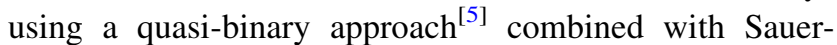
Fraise analysis. ${ }^{[6]}$ They concluded that the interdiffusion coefficients were not sensitive to the compositions of their diffusion couples and can be approximated by the tracer diffusion coefficients. They attributed the observed sluggish diffusion in HEAs to the high normalized activation energies $Q / T_{m}\left(Q\right.$ is the activation energy and $T_{m}$ is the melting temperature of the alloy). Kulkarni and Chauhan ${ }^{[7]}$ investigated the interdiffusion at $1000{ }^{\circ} \mathrm{C}$ in the $\mathrm{Co}-\mathrm{Cr}$ - $\mathrm{Fe}$ $\mathrm{Ni}$ quaternary system, which is an essential constituent system of several HEAs. The main and cross interdiffusion coefficients were determined from concentrations and interdiffusion fluxes developed in a single diffusion couple. Their data indicated that significant diffusional interactions exist in this system and shouldn't be ignored while describing diffusion in HEAs, which was conflicted with the estimations of Tsai et al. ${ }^{[4]}$ Beke and Erdelyi ${ }^{[8]}$ reanalyzed the diffusion coefficients of alloying components in the Co-Cr-Fe-Mn-Ni HEAs based on the experimental data of Tsai et al. ${ }^{[4]}$ Their analysis using the normalized (dimensionless) values of diffusion coefficients versus the homologous temperatures $\left(T_{\mathrm{m}} / T\right)$ also confirmed the sluggish character of diffusion in HEAs. Dabrowa et al. ${ }^{[9]}$ studied the interdiffusion of Al-Co-Cr-Fe-Ni alloys in the temperature range from 1000 to $1100{ }^{\circ} \mathrm{C}$. The tracer diffusion coefficients of all components were determined and further validated against the data obtained by Tsai et al. ${ }^{[4]}$ for diffusion in Co-Cr-Fe-Mn-Ni alloys. Note that, all diffusion coefficients mentioned above $e^{[4,7-9]}$ were obtained from the analysis of concentration profiles of diffusion couples. Vaidya et al. ${ }^{[10]}$ first directly measured the tracer diffusion coefficients of $\mathrm{Ni}$ in equiatomic $\mathrm{CoCrFeNi}$ and $\mathrm{CoCrFeMnNi}$ alloys. The temperature dependence of their measured $\mathrm{Ni}$ tracer diffusion coefficients followed the Arrhenius behavior with respect to both absolute and homologous temperature scales. When the absolute temperature was used, they found that the tracer diffusivity of $\mathrm{Ni}$ was lower in $\mathrm{CoCrFeNi}$ than it was in $\mathrm{CoCrFeMnNi}$. The opposite was found when the homologous temperature was used. In other words, Ni diffuses more sluggish in the 5-component alloy only with respect to the homologous temperature. Their experimental results indicated that the diffusion of Ni in HEAs was not inevitably sluggish. We therefore believe that the diffusion characters in HEAs haven't been systematically investigated and fully understood yet although the term "sluggish diffusion" has often been used to represent one of the core characters of HEAs. Diffusion investigation solely by experimental methods is costly and time-consuming. In order to systematically characterize the diffusion behaviors of HEAs without the need of heavy experimental work, the computational thermodynamics or the so-called CALPHAD (stands for calculation of phase diagrams) approach ${ }^{[1-14]}$ will be used in this study. Since the CALPHAD approach is well established and its applications in HEAs have been covered elsewhere,${ }^{[15-18]}$ only a brief description of this approach will be given here. The CALPHAD approach adopts a phenomenological methodology to obtain a self-consistent database of a multicomponent system based on the descriptions of its constituent lower-order systems, such as binaries and ternaries. This approach, first emerging as an approach for multi-component phase equilibrium calculation, has been applied to a much broader field of materials science and engineering. In addition to thermodynamic database which compiles the Gibbs energies of phases in a system, the CALPHAD method is now being used to develop databases for many phase-related properties, such as molar volume database and atomic mobility database. When combined these databases with the thermodynamic database, many properties can be calculated for multicomponent alloys.

The CALPHAD approach therefore plays an important role in modern materials design and development. The essentials of this approach include robust software and reliable databases. In the present work, the Pandat ${ }^{\mathrm{TM}}$ software $^{[19]}$ and PanHEA ${ }^{[16-18]}$ thermodynamic database are used to perform all the calculations. In order to calculate the diffusion coefficients and carry out diffusion simulations, the according atomic mobility database is also needed. The purpose of this paper is to investigate the diffusion characters of HEAs using an integrated approach of CALPHAD simulation with experimental measurements. This paper will be organized as follows: section 2 describes the experimental work; section 3 presents diffusion modeling of the Co-Cr-Fe-Mn-Ni quinary system followed by database validation in section 4 ; section 5 shows simulation results and discussions, and section 6 is the summary.

\section{Experiment}

Elemental ( $>99.9 \%$ pure) $\mathrm{Ni}, \mathrm{Co}, \mathrm{Fe}, \mathrm{Cr}$, and $\mathrm{Mn}$ metals were carefully weighted and mixed by arc-melting. To ensure homogeneous mixing the arc-melted buttons were flipped and re-melted at least five times before drop-casting into a copper mold. The as-cast ingots were then homogenized at $1200{ }^{\circ} \mathrm{C}$ for $24 \mathrm{~h}$, followed by a water quenching. The homogenized ingots were cut into $\sim 2 \mathrm{~mm}$ thick round discs using electro-discharge machining (EDM). The discs were electro-polished before making into diffusion couples to remove the stressed layer. Quasi-binary couples: (Co$25 \mathrm{Cr}-25 \mathrm{Fe}-25 \mathrm{Ni}) /(\mathrm{Ni}-25 \mathrm{Cr}-25 \mathrm{Fe})$ and $(\mathrm{Co}-20 \mathrm{Cr}-20 \mathrm{Fe}-$ $20 \mathrm{Mn}-20 \mathrm{Ni}) /(\mathrm{Cr}-20 \mathrm{Fe}-20 \mathrm{Mn}-40 \mathrm{Ni})$, all in at. $\%$ were designed to investigate the diffusivity of $\mathrm{Ni}$ and $\mathrm{Co}$ in the 
high entropy alloys, with only $\mathrm{Ni}$ and Co having concentration gradient. The diffusion couples were placed in stainless-steel tubes which were further vacuum-sealed in glass ampules. After annealing the diffusion couples were cross-sectional cut, ground and chemical-mechanical polished. The elemental compositions were measured using scanning electron microscopy (SEM)-energy dispersive $\mathrm{x}$-ray spectroscopy (EDX) with electron energy at about $20 \mathrm{keV}$ (Hitachi TM3030). At least five areas at every farends of our diffusion couples were selected to determine the ingot compositions and the measured compositions were within 1 at.\% from the nominal composition. Therefore, nominal compositions were used for the homogenized ingots in the present study. Three line scans were performed for each diffusion couple to measure the concentration profiles. The lateral resolution of our measurement is around $1 \mu \mathrm{m}$ and all data points are directly from measurement counts without smoothing or fitting. Thus the scattering of these points represents the uncertainties of the composition measurements.

\section{Diffusion Modeling}

\subsection{Atomic Mobility and Diffusivity}

Inspired by the success of the CALPHAD method for describing the Gibbs energies of phases, Andersson and Agren $^{[20]}$ suggested to use this method to describe atomic mobility. The atomic mobility coefficient $M_{i}$ for specie $i$, can be described by Eq 1 as a function of the frequency factor $M_{i}^{o}$ and the activation energy $Q_{i}$ :

$M_{i}=\frac{M_{i}^{o}}{R T} \exp \left(\frac{-Q_{i}}{R T}\right)=\frac{1}{R T} \exp \left(\frac{-Q_{i}+R T \ln M_{i}^{o}}{R T}\right)$

Both $M_{i}^{o}$ and $Q_{i}$ will, in general, depend upon composition, temperature, and pressure. Let $\Delta Q_{i}^{*}=-Q_{i}+R T \ln M_{i}^{o}$ when there is no magnetic effect on the atomic mobility. Similar to the Gibbs energy expression used in the CALPHAD method, the parameter $\Delta Q_{i}^{*}$ of specie $i$ in a given phase can be expressed by a Redlich-Kister ${ }^{[21]}$ polynomial with composition:

$$
\begin{aligned}
\Delta Q_{i}^{*}= & \sum_{j} x_{j} Q_{i}^{j}+\sum_{p} \sum_{j>p} x_{p} x_{j} \sum_{k} Q_{i}^{p j}\left(x_{p}-x_{j}\right)^{k} \\
& +\sum_{p} \sum_{j>p} \sum_{q>j} x_{p} x_{j} x_{q}\left(v_{p j q}^{s}{ }^{s} Q_{i}^{p j q}\right) \\
(s= & p, j, q)
\end{aligned}
$$

The first term on the right hand is like the reference state, and the second term represents binary interactions (when $\mathrm{i}$ is $p$ or $j$ ) or ternary interactions (when $i$ is neither $p$ nor $j$ ).
The third term is for ternary interactions or quaternary interaction. The parameter $v_{p j q}^{s}$ is defined as:

$v_{p j q}^{s}=x_{s}+\frac{1-x_{p}-x_{j}-x_{q}}{3}$

Here, we would like to mention that quaternary and higherorder interaction parameters are very rarely used in the CALPHAD frame. One can see from the Eq 2, the production of mole fraction for a ternary system $\left(x_{p} x_{j} x_{q}\right)$ is smaller than that of a binary system $\left(x_{p} x_{j}\right)$. In the same way, the production of mole fractions for a quaternary or higher-order system will become negligible small and play less significant role when compared to binary and ternary interactions parameters. Thus, most effort for the development of atomic mobility database will focus on its constituent binaries and ternaries.

Using the atomic mobility data with according thermodynamic factors, one can easily obtain the diffusion coefficient. The self or tracer diffusion coefficient $D_{i}^{*}$ is rigorously related to the atomic mobility by a simple relation $D_{i}^{*}=R T M_{i}$, which is independent on the thermodynamic factor. The relationship between interdiffusion coefficient $D_{p q}^{n}$ and atomic mobility with $\mathrm{n}$ as dependent/ reference species can be expressed as:

$D_{p q}^{n}=\sum_{i=1}^{n}\left(\delta_{i p}-x_{p}\right) x_{i} M_{i}\left(\frac{\partial \mu_{i}}{\partial x_{q}}-\frac{\partial \mu_{i}}{\partial x_{n}}\right)$

where the Kronecker delta $\delta_{i p}$ equals to 1 when $i=p$ and 0 otherwise. $\mu_{i}$ is the chemical potential of specie $i$.

\subsection{Assessment of Atomic Mobility}

As mentioned previously, thermodynamic description of the Co-Cr-Fe-Mn-Ni system is adopted from PanHEA and atomic mobility assessments will focus on its constituent lower-order (binary and ternary) systems. There are 10 binary (Co-Cr, Co-Fe, Co-Mn, Co-Ni, Cr-Fe, Cr-Mn, Cr$\mathrm{Ni}, \mathrm{Fe}-\mathrm{Mn}, \mathrm{Fe}-\mathrm{Ni}, \mathrm{Mn}-\mathrm{Ni})$ and 10 ternary $(\mathrm{Co}-\mathrm{Cr}-\mathrm{Fe}, \mathrm{Co}-$ $\mathrm{Cr}-\mathrm{Mn}$, Co-Cr-Ni, Co-Fe-Mn, Co-Fe-Ni, Co-Mn-Ni, Cr$\mathrm{Fe}-\mathrm{Mn}, \mathrm{Cr}-\mathrm{Fe}-\mathrm{Ni}$, Cr-Mn-Ni， Fe-Mn-Ni) sub-systems involved in the Co-Cr-Fe-Mn-Ni quinary system.

Our preliminary atomic mobility assessment for the fcc phase of this quinary system is on the basis of the pioneer work by Campbell et al. ${ }^{[22]}$ Since they developed the database for Ni-based superalloys, their assessments focused on the Ni-rich corner, and the atomic mobility interaction parameters for constituent binaries and ternaries away from Ni-rich corner were not assessed. Our purpose of this study is to investigate the diffusion characters of HEAs, which requires the database to cover almost the entire compositional space rather than focusing on one- or two-element rich region. Thus further improvements on the 
preliminary atomic mobility database are needed for constituent binaries and ternaries using the new available assessments and experimental data. The atomic mobility of fcc phase for the Co-Fe and Co-Ni binaries was studied by Cui et al. ${ }^{[23]}$ Jonsson $^{[24,25]}$ assessed the atomic mobility for the fcc $\mathrm{Cr}-\mathrm{Fe}, \mathrm{Cr}-\mathrm{Ni}$, and $\mathrm{Fe}-\mathrm{Ni}$ alloys. The atomic mobility data for fcc Fe-Mn and Mn-Ni binary systems were modeled in Ref 26 and 27, respectively. In addition to these binary assessments, some of the constituent ternary systems were critically assessed in the literature as well. Cui et al. ${ }^{[28]}$ modeled the atomic mobility in the $\mathrm{Co}-\mathrm{Fe}-\mathrm{Ni}$ ternary fcc alloys. The atomic mobility of fcc $\mathrm{Co}-\mathrm{Cr}-\mathrm{Ni}$ alloys was studied by Chen et al. ${ }^{[29]}$ Assessment of the mobility of fcc $\mathrm{Cr}$-Fe-Ni alloys was carried out by Jon$\operatorname{sson}^{[30]}$ as well. All above assessments are adopted in our current modeling work with modifications for consistency and compatibility. The descriptions of all other constituent binary and ternary systems not mentioned above are obtained via extrapolation. Even though our goal is to develop a fidelity database with all the constituent 10 binaries and 10 ternaries carefully modeled, experimental data are not available for some of the subsystems. This database will be further improved when more experimental data become available.

\section{Database Validation}

The reliability of current atomic mobility database is essential for valuable calculations and understanding the diffusion behaviors of alloys within the Co-Cr-Fe-Mn-Ni system. Therefore, a thorough validation of the mobility database is necessary before making large number of systematic calculations.

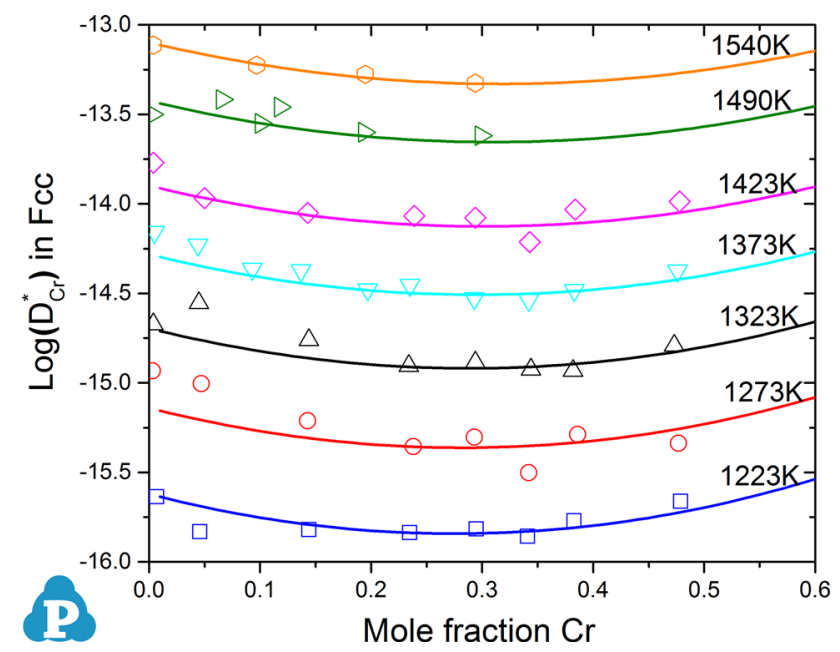

Fig. 1 Tracer diffusion coefficients of $\mathrm{Cr}$ in the $\mathrm{Cr}-\mathrm{Ni}$ binary system at different temperatures with experimental data (symbols) digitized from Ref 24

\subsection{Validation Using the Experimental Data from the Literature}

All diffusion data within the binary and ternary systems summarized in section 3.2 are used to validate the mobility database developed in the preset work. To avoid lengthy paper, only part of the validations are shown here. Figure 1 shows the calculated tracer diffusion coefficients of $\mathrm{Cr}$ in fcc $\mathrm{Cr}-\mathrm{Ni}$ binary alloys at different temperatures. Our calculations (lines) are in good agreement with the experimental data (symbols) digitized from Ref 24 . The calculated interdiffusion coefficients for fcc phase of the Co-Fe binary system at different temperatures are shown in Fig. 2 with the experimental points from Ref 23. Both figures indicate that our calculations can well describe the

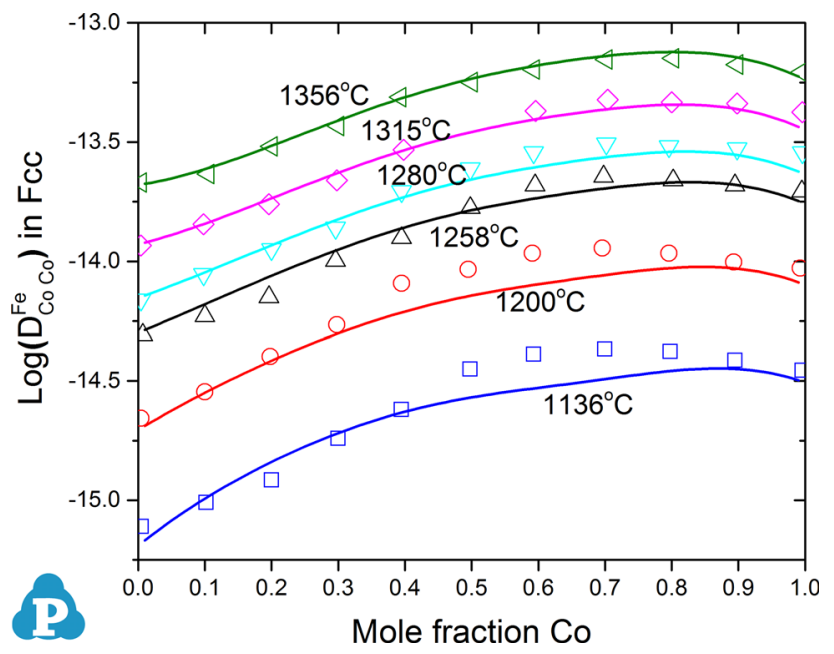

Fig. 2 Calculated interdiffusion coefficients of the Co-Fe binary system at different temperatures with experimental data (symbols) digitized from Ref 23

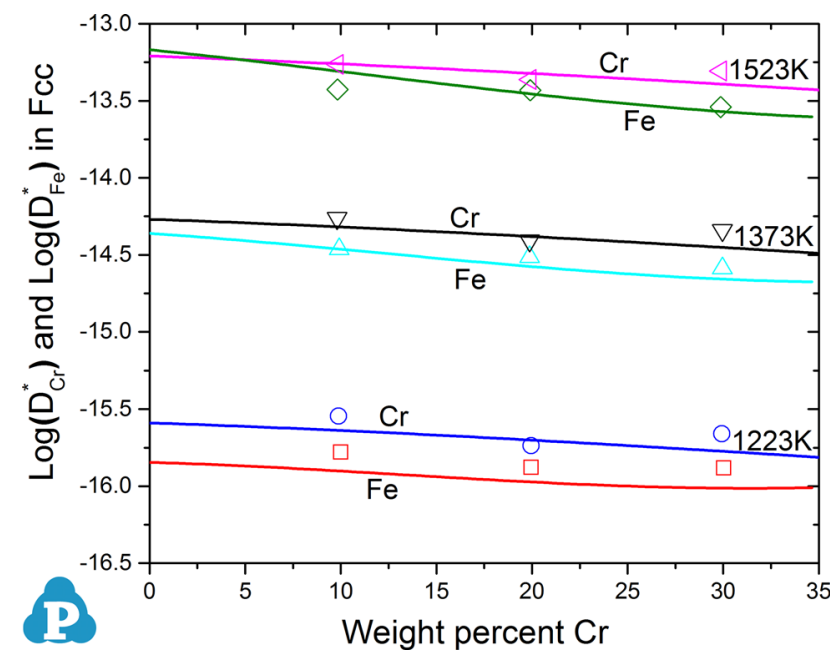

Fig. 3 Composition dependence of the tracer diffusion coefficients of $\mathrm{Fe}$ and $\mathrm{Cr}$ in the $\mathrm{Fe}-\mathrm{Cr}-65 \mathrm{wt} . \% \mathrm{Ni}$ alloys at different temperatures with experimental data (symbols) from Ref 31 
experimental results. It should point out that the tracer diffusion coefficient is thermodynamically independent; therefore the calculated tracer diffusion coefficients (Fig. 2) provide a direct validation of the atomic mobility database. Interdiffusion coefficient, on the other hand, is thermodynamically dependent; therefore the calculated interdiffusion coefficients depend on both the atomic mobility database and the thermodynamic database used in

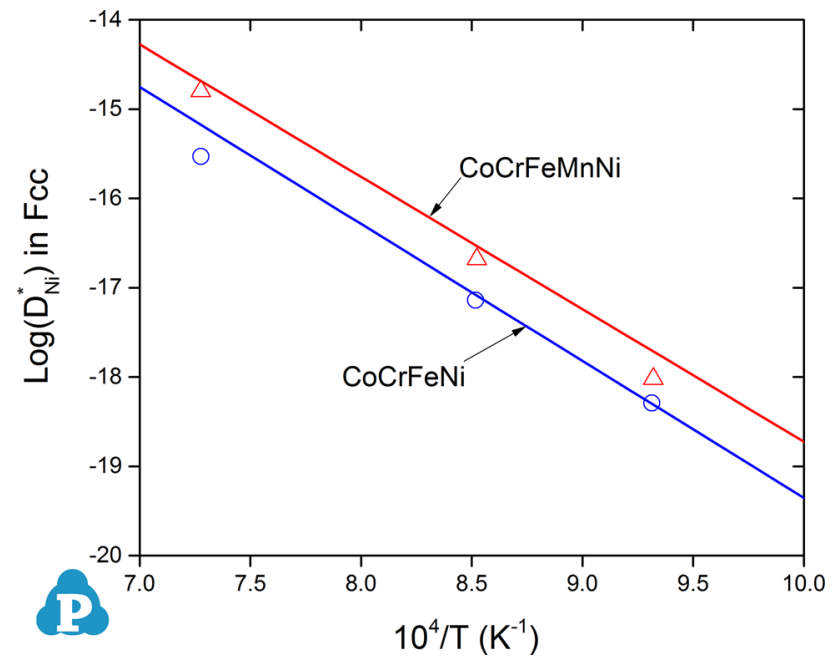

Fig. 4 A comparison of the calculated and measured ${ }^{[10]} \mathrm{Ni}$ tracer diffusivities vs. the inverse of the absolute temperature

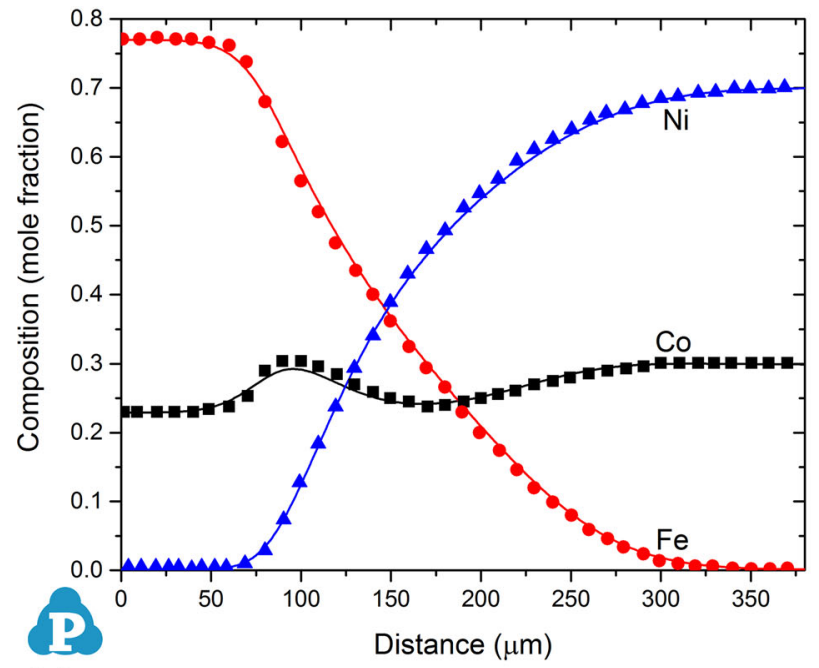

(a)

Fig. 5 Simulation of diffusion couple Co-77Fe/Co-70Ni (at.\%) annealed at $1100{ }^{\circ} \mathrm{C}$ for $196 \mathrm{~h}$ with experimental measurements (symbols) from Ref 32 (a) concentration profiles; (b) diffusion path the calculation. Figure 3 shows the calculated tracer diffusion coefficients of $\mathrm{Cr}$ and $\mathrm{Fe}$ within the fcc $\mathrm{Fe}-\mathrm{Cr}$ $65 \mathrm{wt} . \% \mathrm{Ni}$ alloys at different temperatures. The experimental data are from Million et al. ${ }^{[31]}$ One can see that the tracer diffusion coefficients of both $\mathrm{Cr}$ and $\mathrm{Fe}$ decrease slightly with the increasing of $\mathrm{Cr}$ composition (decreasing of $\mathrm{Fe}$ composition). The directly measured $\mathrm{Ni}$ tracer diffusion coefficients by Vaidya et al. ${ }^{[10]}$ in both the $\mathrm{CoCr}$ $\mathrm{FeNi}$ and $\mathrm{CoCrFeMnNi}$ alloys are very important reference data for the present work. As show in Fig. 4, our calculated $\mathrm{Ni}$ tracer diffusion coefficients for both $\mathrm{CoCrFeNi}$ and $\mathrm{CoCrFeMnNi}$ alloys describe the experimental data of Vaidya et al. ${ }^{[10]}$ reasonably well. The small discrepancies between the calculated values and experimental data locate at higher temperature range for the $\mathrm{CoCrFeNi}$ quaternary alloy and low temperature range for the $\mathrm{CoCrFeMnNi}$ quinary alloy. In addition to the diffusion coefficients, the most common experimental data that can be used to validate the atomic mobility database are the concentration profiles from diffusion couples. In order to simulate the concentration profiles, diffusion contributions from self-, tracer- and inter-diffusivities should all be involved, which means not only the atomic mobility database but also the corresponding thermodynamic database is needed. As shown in Fig. 5, the concentration profiles of $(\mathrm{Co}-77 \mathrm{Fe}) /$ (Co-70Ni) (at.\%) diffusion couple heat-treated at $1100{ }^{\circ} \mathrm{C}$ for $196 \mathrm{~h}$ are simulated. One can see that our simulated

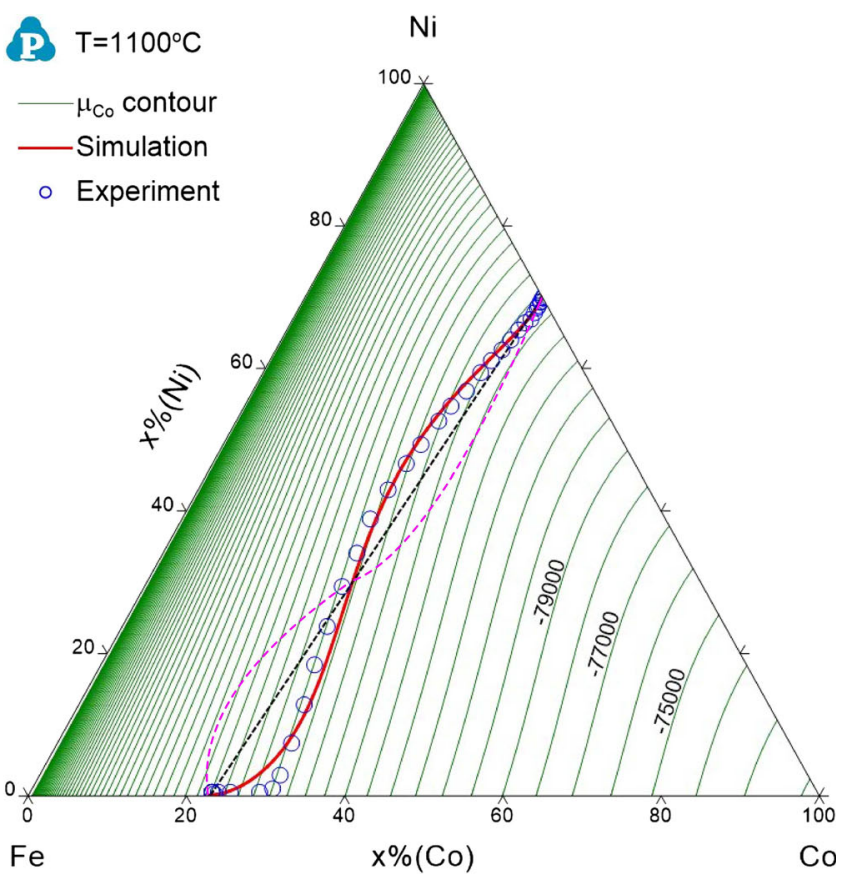

(b)

with chemical potential contour in unit $\mathrm{J} /$ mole *dashed black line and purple curve in $(b)$ are drew schematically for explanation, not simulation results 
concentration profiles can well describe the experimental measurements by Ugaste et al. ${ }^{[32]}$ There is a hump in the concentration profile of $\mathrm{Co}$, which can be explained by the diffusion path shown in Fig. 5(b). As is seen in Fig. 5(b), the current calculated diffusion path as well as the experimental data follows the rule of chemical potential decrease for every diffuse element, while this is not the case for the other two hypothetical diffusion paths, the straight black dashed line connecting these two compositions or the S-shape purple dashed curve in the other direction. For these two assumed diffusion paths, the chemical potential of Co does not continuously decrease, which violates the rule. Figure 6 compares the simulated concentration profiles with the experimental measured ones ${ }^{[7]}$ for the $\mathrm{Co}-\mathrm{Cr}$ Fe-Ni diffusion couples. The nominal compositions of the diffusion couple were (Co-30Cr-20Fe-30Ni)/(Co-20Cr$30 \mathrm{Fe}-20 \mathrm{Ni}$ ) (at.\%). However, their measured concentration profiles indicate that the real compositions of this diffusion couple were slightly different from the nominal compositions. As is seen in Fig. 6(a), large discrepancy is observed between the simulated and experimental measured concentration profiles when the nominal compositions are used for the simulation. The agreement is greatly improved when the real compositions of the diffusion couple are used as is shown in Fig. 6(b). The discrepancy between the simulated and the measured concentration files is still obvious, and further experimental investigation on the diffusion behavior of this important constituent system is needed. Comparison shown in Fig. 6 also reminds us the necessity to carefully analyze the experimental data in the literature for reference, which is critically important for the development of reliable database. Concentration profiles of (Co-29Cr-22Fe-5Mn-22Ni)/(Co-17Cr-22Fe-17Mn-22Ni)

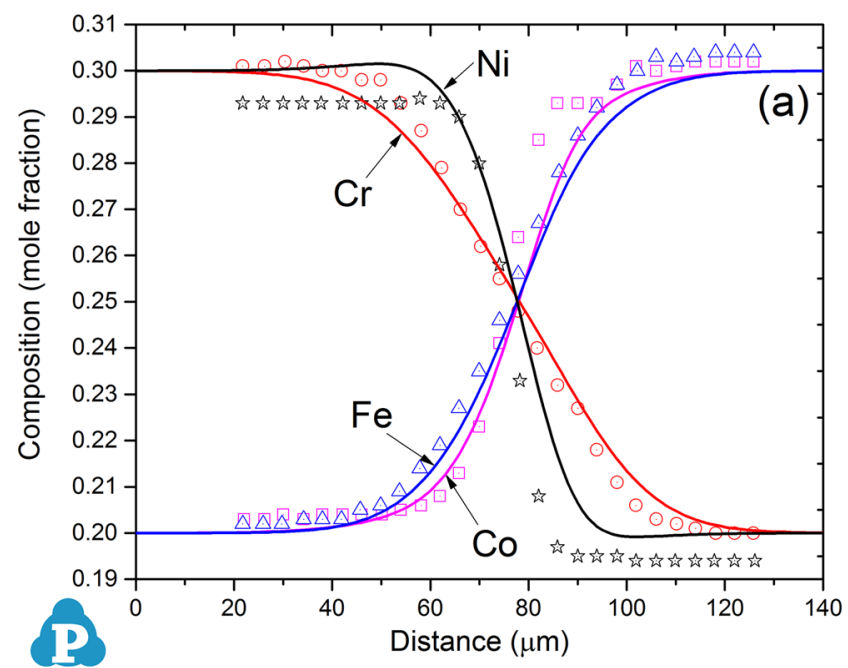

(a) (at.\%) diffusion couple annealed at $1000{ }^{\circ} \mathrm{C}$ for $100 \mathrm{~h}$ were measured by Tsai et al. ${ }^{[4]}$ As is shown in Fig. 7, our simulated results can well reproduce their experimental data. It should be pointed out that this diffusion couple is actually a "quasi-binary" diffusion couple, i.e., only the compositions of $\mathrm{Cr}$ and $\mathrm{Mn}$ vary while compositions of the other three components are constant in the diffusion couple. Since the diffusional interactions or the cross effects of various diffusing species play an important role in the diffusion kinetics of multicomponent alloys, more experimental work is needed to better understand the diffusional kinetics in the Co-Cr-Fe-Mn-Ni HEAs.

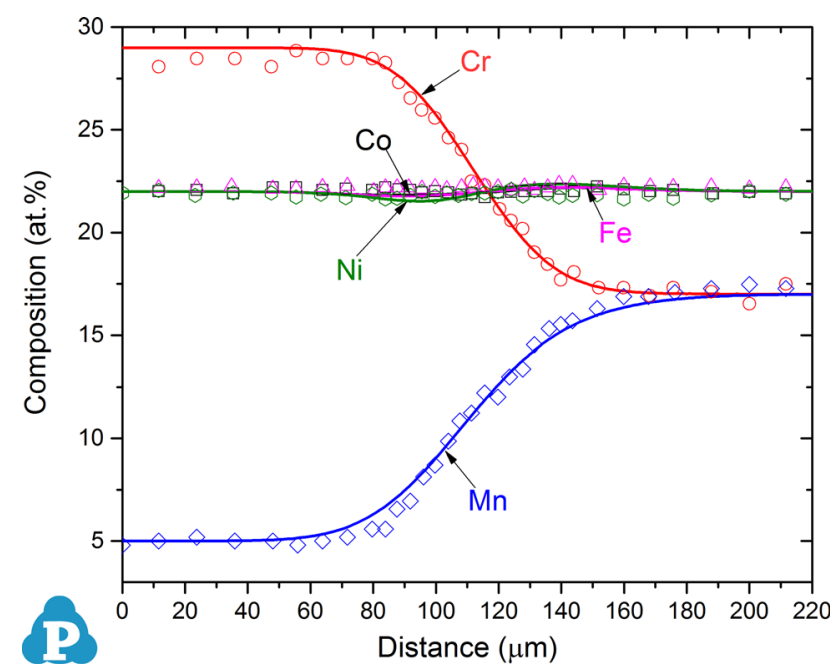

Fig. 7 Simulated concentration profiles of $\mathrm{Co}_{22} \mathrm{Cr}_{29} \mathrm{Fe}_{22} \mathrm{Mn}_{5} \mathrm{Ni}_{22} /$ $\mathrm{Co}_{22} \mathrm{Cr}_{17} \mathrm{Fe}_{22} \mathrm{Mn}_{17} \mathrm{Ni}_{22}$ (at.\%) diffusion couple annealed at $1000{ }^{\circ} \mathrm{C}$ for $100 \mathrm{~h}$ with experimental data (symbols) from Ref 4

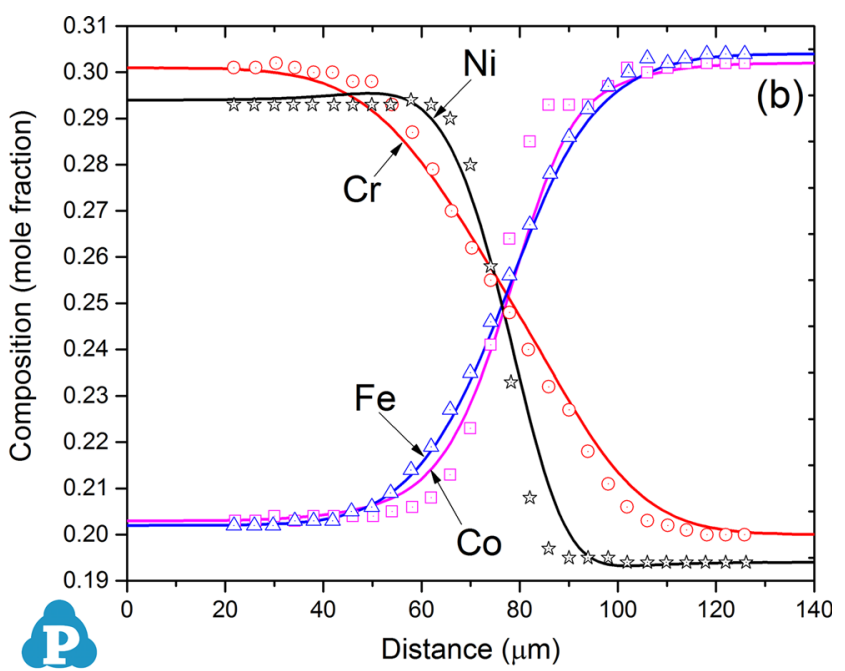

(b)

Fig. 6 Simulated concentration profiles of $\mathrm{Co}-30 \mathrm{Cr}-20 \mathrm{Fe}-30 \mathrm{Ni} / \mathrm{Co}-20 \mathrm{Cr}-30 \mathrm{Fe}-20 \mathrm{Ni}$ (at.\%) diffusion couple annealed at $1000{ }^{\circ} \mathrm{C}$ for $100 \mathrm{~h}$ with experimental data (symbols) of Ref 7 (a) nominal alloy composition; (b) measured alloy composition 


\subsection{Validation Using the Experimental Data of this Work}

As discussed in section 4.1, more experimental measurements are needed for the $\mathrm{Co}-\mathrm{Cr}-\mathrm{Fe}-\mathrm{Ni}$ quaternary system and the Co-Cr-Fe-Mn-Ni quinary system. In this work, two diffusion couples were prepared based on these quaternary and quinary systems, and simulations were performed to compare with the measured concentration profiles. Figure 8 compares the simulated and measured concentration profiles of the $(\mathrm{Co}-25 \mathrm{Cr}-25 \mathrm{Fe}-25 \mathrm{Ni}) /(\mathrm{Ni}-$

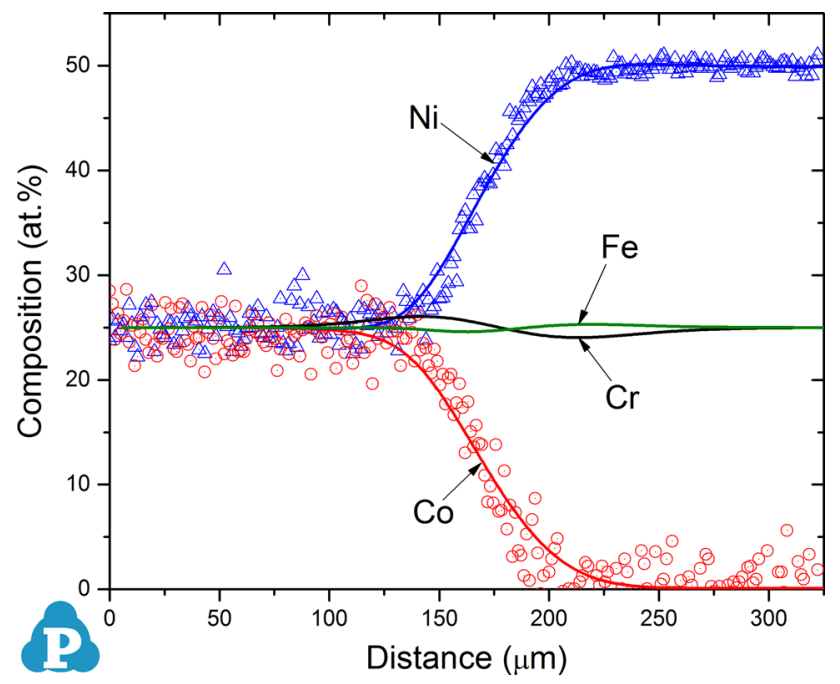

Fig. 8 Simulated concentration profiles of $\mathrm{Co}_{25} \mathrm{Cr}_{25} \mathrm{Fe}_{25} \mathrm{Ni}_{25} / \mathrm{Ni}_{50}$ $\mathrm{Cr}_{25} \mathrm{Fe}_{25}$ (at.\%) diffusion couple annealed at $1120{ }^{\circ} \mathrm{C}$ for $48 \mathrm{~h}$ with experimental data (symbols) of this work

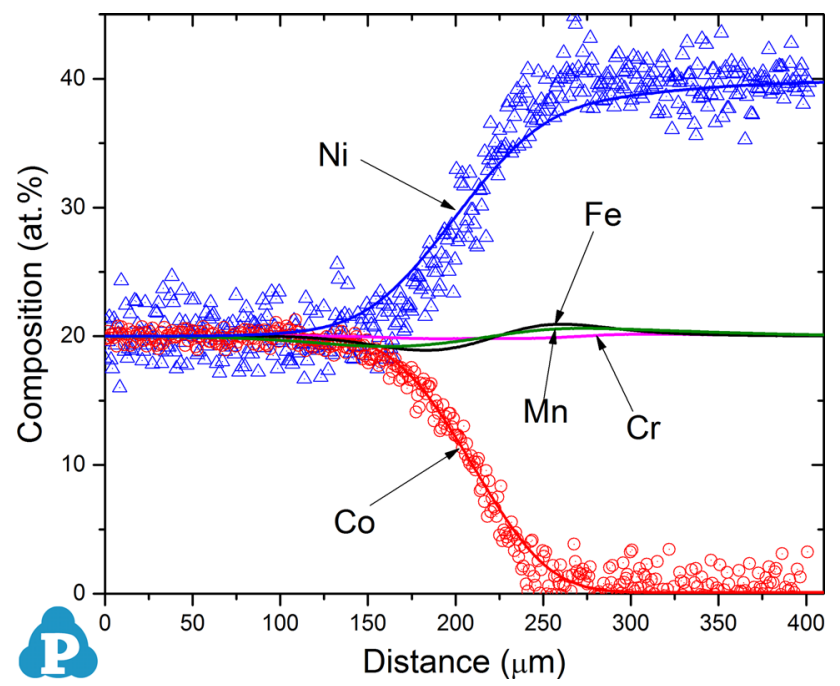

Fig. 9 Simulated concentration profiles of $\mathrm{Co}_{20} \mathrm{Cr}_{20} \mathrm{Fe}_{20} \mathrm{Mn}_{20} \mathrm{Ni}_{20} /$ $\mathrm{Cr}_{20} \mathrm{Fe}_{20} \mathrm{Mn}_{20} \mathrm{Ni}_{40}$ (at.\%) diffusion couple annealed at $1070{ }^{\circ} \mathrm{C}$ for $94.5 \mathrm{~h}$ with experimental data (symbols) of this work
$25 \mathrm{Cr}-25 \mathrm{Fe}$ ) (at.\%) diffusion couple annealed at $1120{ }^{\circ} \mathrm{C}$ for $48 \mathrm{~h}$. The good agreement provides a validation of the reliability of our current atomic mobility database for the fcc $\mathrm{Co}-\mathrm{Cr}-\mathrm{Fe}-\mathrm{Ni}$ system. Experimental investigation on the $(\mathrm{Co}-20 \mathrm{Cr}-20 \mathrm{Fe}-20 \mathrm{Mn}-20 \mathrm{Ni}) /(\mathrm{Cr}-20 \mathrm{Fe}-20 \mathrm{Mn}-40 \mathrm{Ni})$ (at.\%) diffusion couple annealed at $1070{ }^{\circ} \mathrm{C}$ for $94.5 \mathrm{~h}$ was also carried out in this work. Different from the work of Tsai et al. ${ }^{[4]}$ which focused on the diffusion behaviors of $\mathrm{Cr}$ and $\mathrm{Mn}$, our experiments investigate the interdiffusion of Co and Ni. As shown in Fig. 9, our simulated concentration profiles agree very well with our experimental measurements.

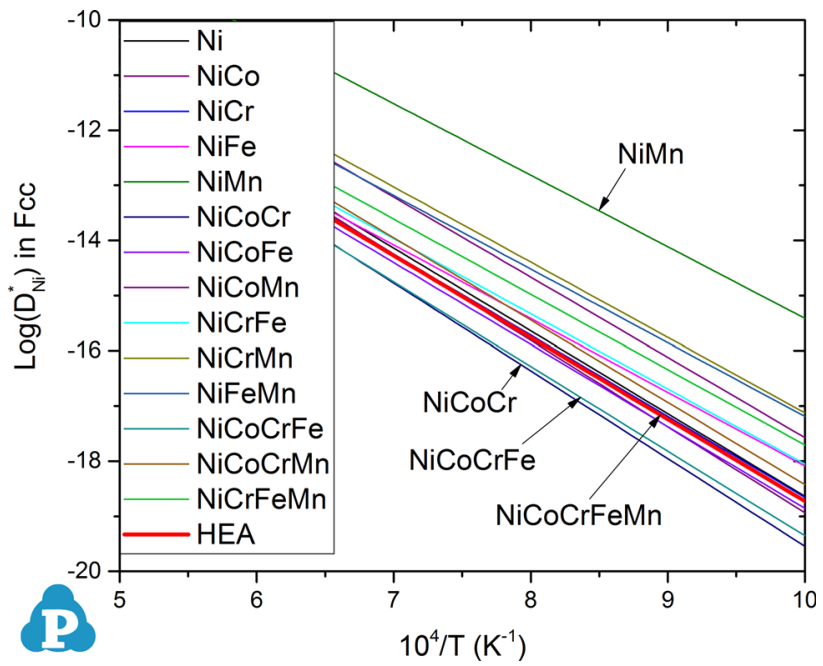

Fig. 10 Calculated Ni tracer diffusion coefficients vs. the inverse of the absolute temperature for Ni-related alloys at equiatomic ratios in the Co-Cr-Fe-Mn-Ni system

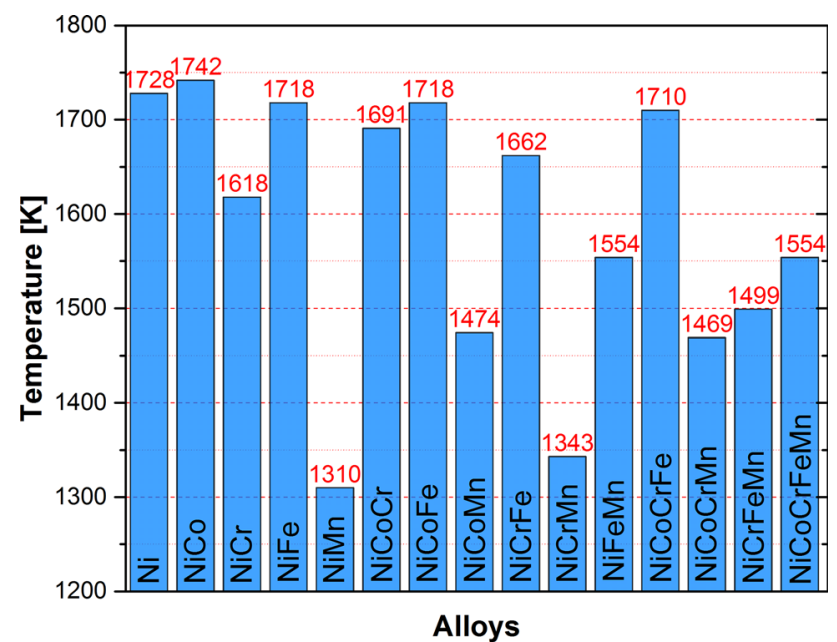

Fig. 11 Calculated melting temperatures of the Ni-related alloys at equiatomic ratios in the $\mathrm{Co}-\mathrm{Cr}-\mathrm{Fe}-\mathrm{Mn}-\mathrm{Ni}$ system 


\section{Application of the Co-Cr-Fe-Mn-Ni Database and Discussion}

After various validations of the atomic mobility database using experimental data from both literature and this work in section 4, we use this database to systematically investigate the diffusional characters in the Co-Cr-Fe-Mn-Ni system. Here, we would like to emphasize again that the most important advantage of the CALPHAD approach is to predict properties of unknown region in a multicomponent system using the database parameters obtained from its constituent low-order systems. Thus the current database (thermodynamic + atomic mobility) enables us to explore the diffusional behaviors of every component in the binary,

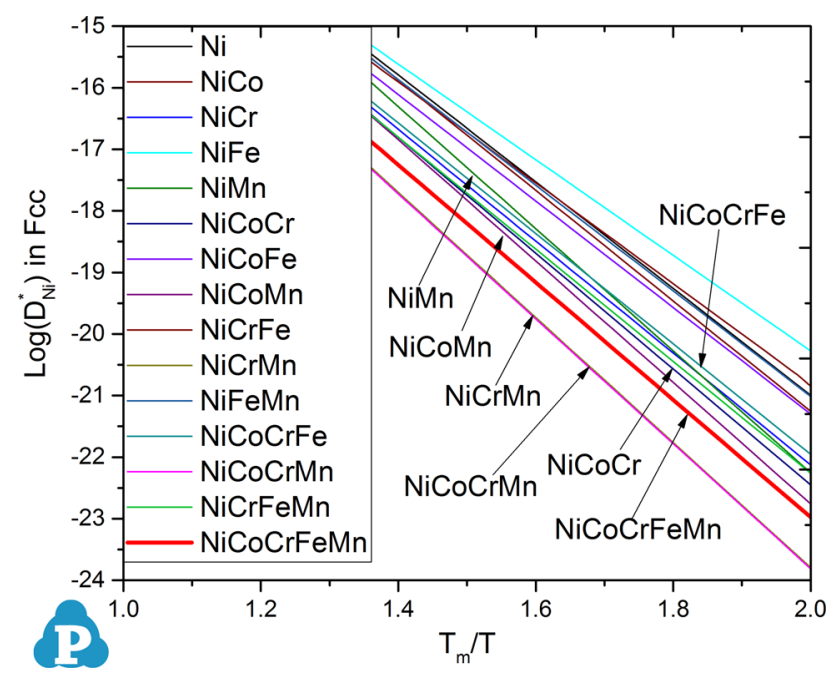

Fig. 12 Calculated $\mathrm{Ni}$ tracer diffusivities vs. the inverse of the homologous temperature

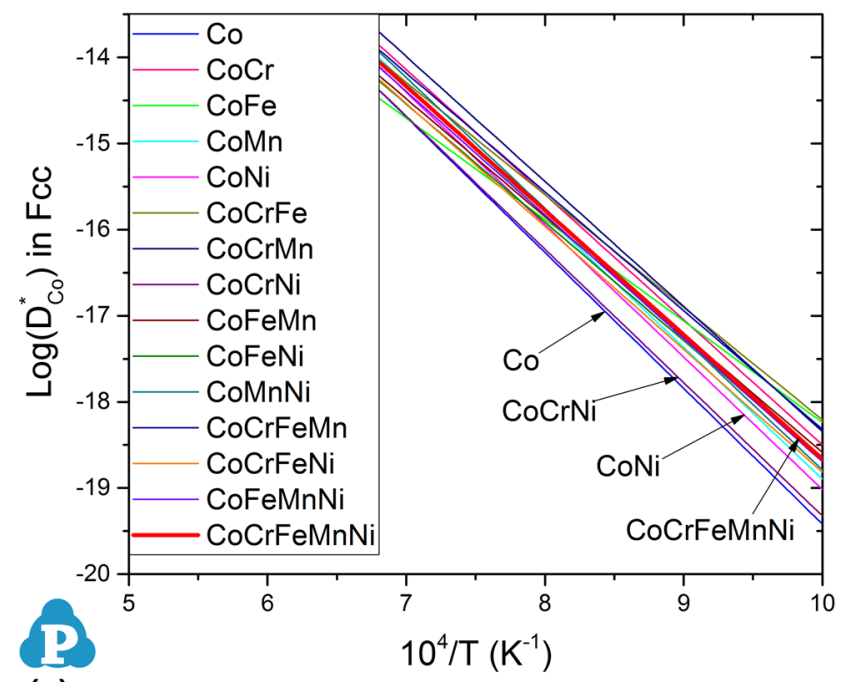

(a) ternary, quaternary, and quinary fcc alloys within the CoCr-Fe-Mn-Ni system.

As mentioned in the introduction section, one of the core effects of HEAs is the sluggish diffusion. This effect has also been confirmed in some literatures. ${ }^{[4,7-10]}$ For a better understanding of "sluggish diffusion" effect, the tracer diffusivity of $\mathrm{Ni}$ is calculated in pure $\mathrm{Ni}, \mathrm{Ni}-\mathrm{X}$ binaries, $\mathrm{Ni}-\mathrm{X}-\mathrm{Y}$ ternaries, $\mathrm{Ni}-\mathrm{X}-\mathrm{Y}-\mathrm{Z}$ quaternaries, as well as $\mathrm{CoCrFeMnNi}$ quinary with equiatomic ratio. As is shown in Fig. 10, the tracer diffusivity of $\mathrm{Ni}$ in NiMn can be one to four orders of magnitude higher than those in other alloys. Even though the line representing the tracer diffusion coefficient of $\mathrm{Ni}$ in $\mathrm{CoCrFeMnNi}$ locates below those of many others, it is not the lowest. In other words, $\mathrm{Ni}$ does not inevitably diffuse more sluggish in the so-called CoCrFeMnNi HEA than it does in other alloys with fewer components.

Note that, many publications plotted tracer diffusivity as a function of homologous temperature $\left(T_{\mathrm{m}} / T\right)$ instead of the absolute temperature $(1 / T)$. The reason given is that elements move much more aggressively at temperature closer to the melting temperature, and therefore it is not fair to compare the tracer diffusivity of an element in different alloys at the same absolute temperature when their melting temperatures are significantly different. Several papers ${ }^{[4,7-10]}$ claimed that the tracer diffusivity of $\mathrm{Ni}$ in the CoCrFeMnNi HEA is the lowest comparing to other alloys with fewer components when homologous temperature $\left(T_{\mathrm{m}} / T\right)$ was used. To make it comparable with the literature work, homologous temperature is used in this work as well. Figure 11 shows the calculated melting temperatures of pure $\mathrm{Ni}$ and all the $\mathrm{Ni}$ involving alloys with equiatomic ratio in the $\mathrm{Co}-\mathrm{Cr}-\mathrm{Fe}-\mathrm{Mn}$ $\mathrm{Ni}$ system. Here we would like to mention that the calculated melting temperatures of pure $\mathrm{Ni}$ and all binary alloys should

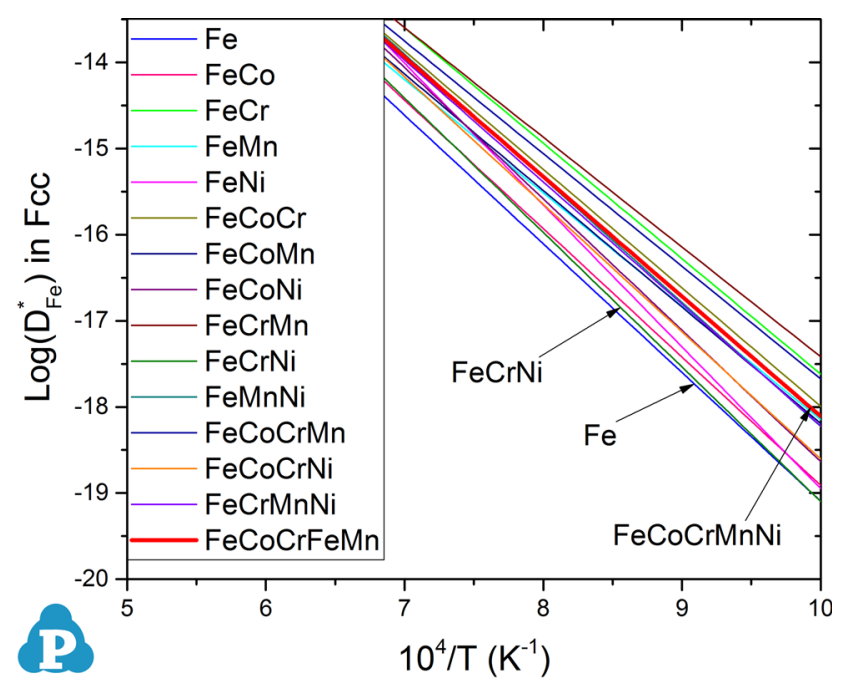

(b)

Fig. 13 Calculated tracer diffusion coefficients of $\mathrm{Co}$ and $\mathrm{Fe}$ vs. the inverse of the absolute temperature for Co- and Fe-related equiatomic alloys in the Co-Cr-Fe-Mn-Ni system 
be accurate since they have been well evaluated. While, the accuracy of melting temperatures for the ternary and higherorder alloys will depend on the available experimental data in the literature. The melting temperatures of $\mathrm{CoCrFeNi}$ and CoCrFeMnNi alloys are measured to be 1717 and $1607 \mathrm{~K}$, respectively, by Vaidya et al. ${ }^{[10]}$ The calculated values from our thermodynamic database are $1712 \mathrm{~K}$ for the $\mathrm{CoCrFeNi}$ alloy and $1593 \mathrm{~K}$ for the CoCrFeMnNi alloy, which indicates that our calculated melting temperatures are reasonable especially at high temperatures. As shown in Fig. 11, the melting temperatures for the alloys containing $\mathrm{Mn}$ tend to be 100-200 ${ }^{\circ} \mathrm{C}$ below the melting temperatures of other alloys. The melting temperature of the NiMn binary alloy is the lowest $\left(1319{ }^{\circ} \mathrm{C}\right)$, which is $\sim 200{ }^{\circ} \mathrm{C}$ below those of $\mathrm{Mn}$ containing alloys, and $\sim 400{ }^{\circ} \mathrm{C}$ below those alloys containing no $\mathrm{Mn}$. We thus expect relatively large offset of $\mathrm{Ni}$

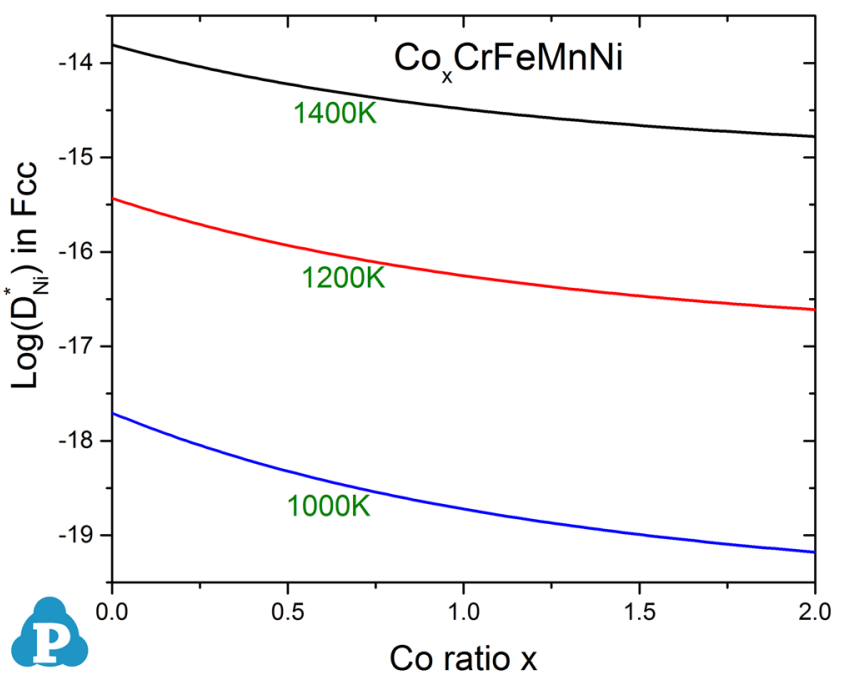

(a)

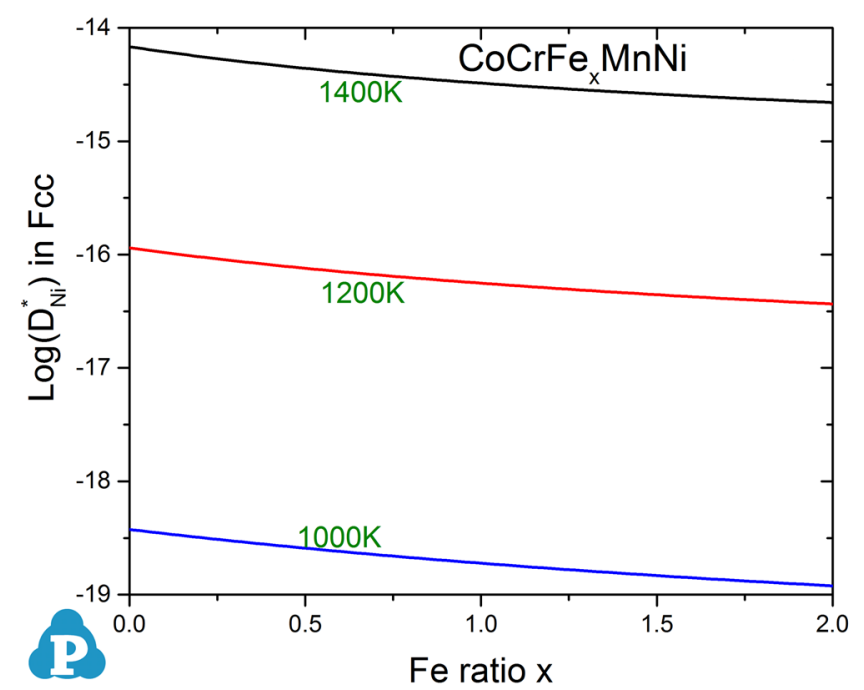

(c) diffusion in alloys with $\mathrm{Mn}$ in the Arrhenius diagrams when the homologous temperature $\left(T_{\mathrm{m}} / T\right)$ is used, especially for that of the NiMn binary alloy. As shown in Fig. 12, the tracer diffusivity of $\mathrm{Ni}$ in Mn containing alloys does become relatively low due to their low melting temperatures. The line for NiMn binary alloy is significantly higher than those for other alloys in Fig. 10, it is now located within the same level as others in Fig. 12. One can also see that the Ni tracer diffusivity in the NiCoCrFeMn alloy is indeed lower than those for most of the alloys, but it is higher than that in the $\mathrm{NiCoCrMn}$ alloy. In other words, the diffusion of $\mathrm{Ni}$ does not necessarily become more sluggish with the increase of number of components.

In addition to $\mathrm{Ni}$, tracer diffusivity of $\mathrm{Co}$ and $\mathrm{Fe}$ are also calculated using the mobility database developed in this work for the Co-Cr-Fe-Mn-Ni system as shown in Fig. 13.

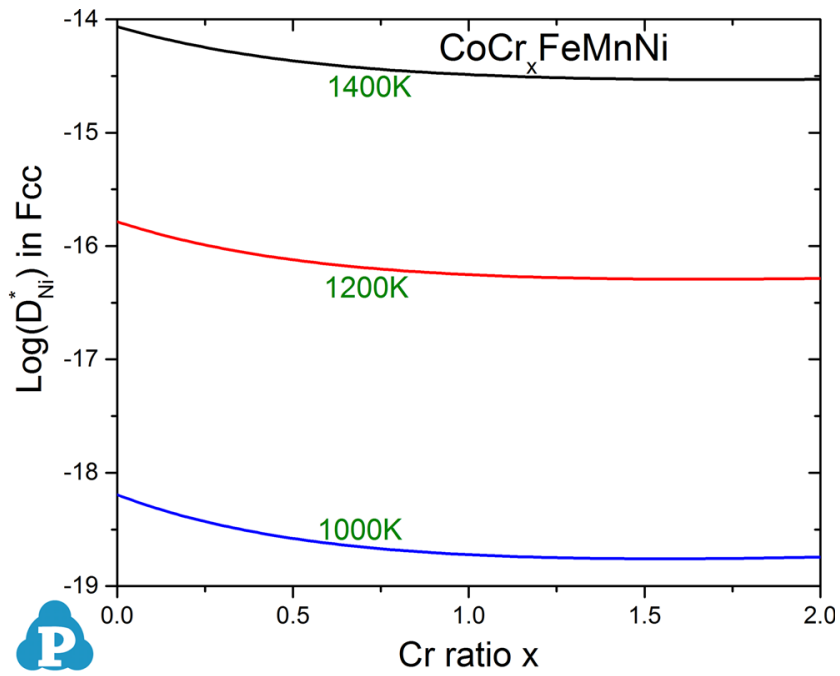

(b)

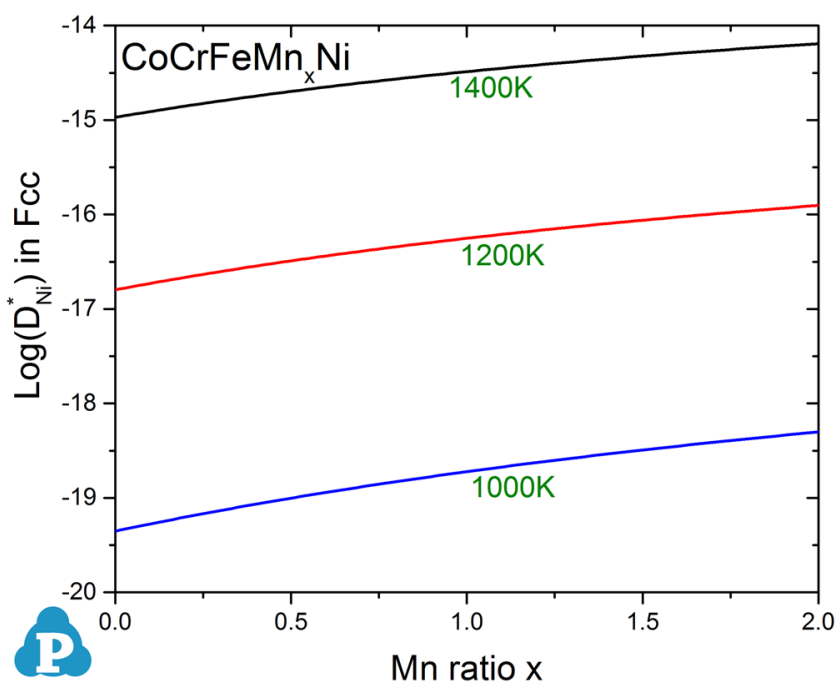

(d)

Fig. 14 Calculated composition dependence of $\mathrm{Ni}$ tracer diffusivities in the Co-Cr-Fe-Mn-Ni system at different temperatures 
In the plots, the absolute temperature $(1 / T)$ is used. As is seen again, the chosen element does not necessarily show the most sluggish diffusion in the 5-component alloys. In addition to the temperature dependence of tracer diffusivity, the composition dependence is also of great interest. In the work of Tsai et al., ${ }^{[4]}$ they assumed that the diffusion coefficients were not sensitive to the composition in their diffusion couples. In order to verify this assumption, we calculated composition dependence of $\mathrm{Ni}$ tracer diffusivity in the Co-Cr-Fe-Mn-Ni system at several different temperatures. The calculate results are shown in Fig. 14. From this figure it is seen that the tracer diffusivity of Ni reduced with the increase in ratio of $\mathrm{Co}, \mathrm{Cr}$, or $\mathrm{Fe}$ at fixed temperatures. While the effect of $\mathrm{Mn}$ on the Ni tracer diffusivity shows exactly the opposite tendency. Thus one may not expect the diffusion of $\mathrm{Ni}$ is inevitably more sluggish in concentrated solid solution alloys with increased number of components. In fact, diffusion behavior depends strongly on the alloy composition instead of the number of components.

\section{Summary}

In this work, CALPHAD approach is used to develop the mobility database of the Co-Cr-Fe-Mn-Ni. This database was validated by both the available experimental data from the literatures and the experimental investigations carried out in the present work on the $(\mathrm{Co}-25 \mathrm{Cr}-25 \mathrm{Fe}-25 \mathrm{Ni}) /(\mathrm{Ni}-$ $25 \mathrm{Cr}-25 \mathrm{Fe})$ and $(\mathrm{Co}-20 \mathrm{Cr}-20 \mathrm{Fe}-20 \mathrm{Mn}-20 \mathrm{Ni}) /(\mathrm{Cr}-20 \mathrm{Fe}-$ $20 \mathrm{Mn}-40 \mathrm{Ni}$ ) (at.\%) diffusion couples. This database was then used to perform a series of calculations to understand the diffusion behavior of elements in equiatomic binary alloys, ternary alloys, quaternary alloys, as well as the quinary alloys. Systematic calculations were performed for the tracer diffusivity of $\mathrm{Ni}$ to demonstrate that the selected element does not inevitably diffuse the most sluggish in the so-called HEA made of the five components with equiatomic ratio. Following the published work, the calculations were made for both the absolute temperature $(1 / T)$ and homologous temperature $\left(T_{\mathrm{m}} / T\right)$. Even though the use of homologous temperature seems to be more physics sound for academy research, it is more intuitive to use absolute temperature $(1 / T)$ for industrial applications.

\footnotetext{
Acknowledgments This experimental work (H.B. and K.J.) was supported as part of the Energy Dissipation to Defect Evolution (EDDE), an Energy Frontier Research Center funded by the U.S. Department of Energy, Office of Science, Basic Energy Sciences. This manuscript has been authored by UT-Battelle, LLC under Contract No. DE-AC05-00OR22725 with the U.S. Department of Energy. The United States Government retains and the publisher, by accepting the article for publication, acknowledges that the United States Government retains a non-exclusive, paid-up, irrevocable, world-wide license to publish or reproduce the published form of this
}

manuscript, or allow others to do so, for United States Government purposes. The Department of Energy will provide public access to these results of federally sponsored research in accordance with the DOE Public Access Plan (http://energy.gov/downloads/doe-publicaccess-plan).

\section{References}

1. J.-W. Yeh et al., Nanostructured High-Entropy Alloys with Multiple Principal Elements: Novel Alloy Design Concepts and Outcomes, Adv. Eng. Mater., 2004, 6, p 299-303

2. B. Cantor et al., Microstructural Development in Equiatomic Multicomponent Alloys, Mater. Sci. Eng. A, 2004, 375-377, p 213-218

3. D.B. Miracle and O.N. Senkov, A Critical Review of High Entropy Alloys and Related Concepts, Acta Mater., 2017, 122, p 448-511

4. K.-Y. Tsai, M.-H. Tsai, and J.-W. Yeh, Sluggish Diffusion in CoCr-Fe-Mn-Ni High-Entropy Alloys, Acta Mater., 2013, 61(13), p 4887-4897

5. A. Paul, A Pseudobinary Approach to Study Interdiffusion and the Kirkendall Effect in Multicomponent Systems, Philos. Mag., 2013, 93(18), p 2297-2315

6. F. Sauer and V. Freise, Diffusion in Binary Mixtures with Volume Change, Rep. Bunsen Soc. Phys. Chem., 1962, 66(4), p 353362

7. K. Kulkarni and G.P.S. Chauhan, Investigations of Quaternary Interdiffusion in a Constituent System of High Entropy Alloys, AIP Adv., 2015, 6, p 097162

8. D.L. Beke and G. Erdélyi, On the Diffusion in High-Entropy Alloys, Mater. Lett., 2016, 164, p 11-113

9. J. Dabrowa et al., Interdiffusion in the FCC-Structured Al-Co-CrFe-Ni High Entropy Alloys: Experimental Studies and Numerical Simulations, J. Alloys Compd., 2016, 674, p 455-462

10. M. Vaidya et al., Ni Tracer Diffusion in $\mathrm{CoCrFeNi}$ and $\mathrm{CoCr}-$ FeMnNi High Entropy Alloys, J. Alloys Compd., 2016, 688, p 994-1001

11. L. Kaufman and H. Bernstein, Computer Calculation of Phase Diagrams, Academic Press, New York, 1970

12. M. Hillert, Phase Transformations, ASM, Cleveland, OH, 1968

13. Y.A. Chang et al., Phase Diagram Calculation: Past, Present and Future, Prog. Mater. Sci., 2004, 49, p 313-345

14. Y.A. Chang, Phase Diagram Calculations in Teaching, Research, and Industry, Metall. Trans. B, 2006, 37B, p 7-39

15. F. Zhang et al., An Understanding of High Entropy Alloys from Phase Diagram Calculations, CALPHAD, 2014, 45, p 1-10

16. C. Zhang et al., Computational Thermodynamics Aided HighEntropy Alloy Design, JOM, 2012, 64(7), p 839-845

17. C. Zhang and M.C. Gao, CALPHAD Modeling of High-Entropy Alloys, High-Entropy Alloys-Fundamentals and Applications, M.C. Gao et al., Ed., Springer, Switzerland, 2016, p 536

18. C. Zhang et al., Understanding Phase Stability of Al-Co-Cr-Fe-Ni High Entropy Alloys, Mater. Des., 2016, 109, p 425-433

19. Pandat ${ }^{\mathrm{TM}}$, Thermodynamic Calculations and Kinetic Simulations. CompuTherm, LLC, Middleton, WI, USA-53562.

20. J.O. Andersson and J. Ågren, Models for Numerical Treatment of Multicomponent Diffusion in Simple Phases, J. Appl. Phys., 1992, 72(4), p 1350-1355

21. O. Redlich and A.T. Kister, Algebraic Representation of Thermodynamic Properties and the Classification of Solutions, Ind. Eng. Chem., 1948, 40, p 345-348

22. C.E. Campbell, W.J. Boettinger, and U.R. Kattner, Development of a Diffusion Mobility Database for Ni-Base Superalloys, Acta Mater., 2002, 50, p 775-792 
23. Y.-W. Cui et al., Computational Study of Atomic Mobility for fcc Phase of Co-Fe and Co-Ni Binaries, J. Phase Equilib. Diffus., 2008, 29(1), p 2-10

24. B. Jonsson, Assessment of the Mobilities of $\mathrm{Cr}, \mathrm{Fe}$, and $\mathrm{Ni}$ in Binary fcc Cr-Fe and Cr-Ni Alloys, Scand. J. Metall., 1995, 24, p 21-27

25. B. Jonsson, Mobilities in Fe-Ni Alloys: Assessment of the Mobilities of $\mathrm{Fe}$ and $\mathrm{Ni}$ in fcc Fe-Ni Alloys, Scand. J. Metall., 1994, 23, p 201-208

26. Y. Liu et al., Atomic Mobilities, Uphill Diffusion and Proeutectic Ferrite Growth in Fe-Mn-C Alloys, Calphad, 2009, 33(3), p 614623

27. W. Zhang et al., Atomic Mobility, Diffusivity and Diffusion Growth Simulation for fcc Cu-Mn-Ni Alloys, Calphad, 2011, 35, p 367-375
28. Y.W. Cui et al., Computational Study of Atomic Mobility in CoFe-Ni Ternary Fcc Alloys, J. Phase Equilib. Diffus., 2008, 29(4), p 312-321

29. J. Chen et al., Atomic Mobilities, Interdiffusivities and Their Related Diffusional Behaviors in fcc Co-Cr-Ni Alloys, J. Alloys Compd., 2015, 621, p 428-433

30. B. Jonsson, Assessment of the Mobilities of $\mathrm{Cr}, \mathrm{Fe}$, and $\mathrm{Ni}$ in $\mathrm{fcc}$ Cr-Fe-Ni Alloys, Z. Metallkd., 1995, 86, p 686-692

31. B. Million, J. Ruzickova, and J. Vrestal, Diffusion in Fe-Ni-Cr Alloys with an Fcc Lattice, Mater. Sci. Eng., 1985, 72, p 85-100

32. Y.E. Ugaste, A.A. Kodentsov, and F.V. Loo, Investigation of the Interdiffusion and Kirkendall Effect in the Co-Ni-Fe System: I. Redistribution of Component Concentrations in the Diffusion Zone and Shift of Inert Markers, Phys. Met. Metall., 2004, 97(3), p 298-306 